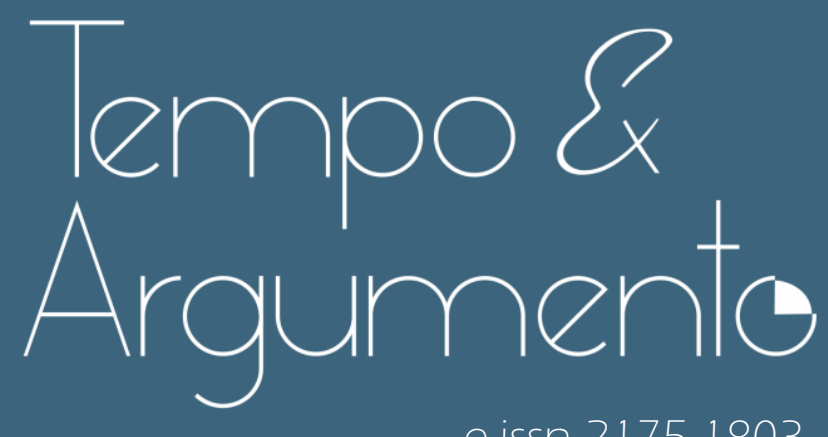

e-issn 2175-1803

O verde oliva na TV: o advento da televisão em

cores pelo regime militar no Brasil

- Eduardo Amando de Barros Filho

Doutor em História pela Universidade Estadual Paulista Júlio de Mesquita Filho (UNESP).

Professor da Universidade do Oeste Paulista (UNOESTE).

Jaú, SP - BRASIL

lattes.cnpq.br/1752742006206941

e.amando@terra.com.br

(D) orcid.org/0000-0002-0832-9850

Para citar este artigo:

BARROS FILHO, Eduardo Amando de. O verde oliva na TV: o advento da televisão em cores pelo regime militar no Brasil. Tempo e Argumento, Florianópolis, v. 13, n. 32, e0204, jan./abr. 2021.

doi http://dx.doi.org/10.5965/2175180313322021 e0204

Recebido: 22/06/2020

Aprovado: $21 / 12 / 2020$ 


\title{
O verde oliva na TV: o advento da televisão em cores pelo regime militar no Brasil
}

\begin{abstract}
Resumo
O presente artigo tem como objetivo tratar da determinação do regime militar para implantação da televisão em cores no Brasil. Para tanto, recorremos à bibliografia sobre o tema e matérias jornalísticas dos periódicos: O Estado de $S$. Paulo, Diário de S. Paulo, O Globo, Jornal do Brasil e Veja. Portanto, temos como intento trazer à luz os interesses dos militares na difusão da televisão em cores, como: controle maior sobre o setor televisivo, pioneirismo na América do Sul, avanço tecnológico e incentivo à indústria nacional.
\end{abstract}

Palavras-chave: Brasil - Política e governo - 1964-1985. Televisão - Brasil. Televisão a cores.

\section{Green oliva on TV: the advent of color television by military regime in Brazil}

\begin{abstract}
This article aims to address the determination of the military regime for the implementation of color television in Brazil. For that, we used the bibliography on the subject and journalistic articles of the periodicals: O Estado de S. Paulo, Diário de S. Paulo, O Globo, Jornal do Brasil and Veja. Therefore, we aim to bring the interests of the military to light in color television, such as: greater control over the television sector, pioneering in South America, technological advancement and incentive to national industry.
\end{abstract}

Keywords: Brazil - Politics and government - 1964-1985. Brasilian television. Color TV.

\section{Introdução}

O governo militar determinou o dia 31 de março de 1972 para inaugurar oficialmente a televisão em cores no Brasil. Data escolhida estrategicamente para atrelar essa novidade aos festejos do oitavo ano do golpe. A década de 1970 foi o momento de consolidação da televisão como principal meio de comunicação brasileiro. Muito desse desenvolvimento se deve à ascensão dos militares ao 
poder, investindo estrategicamente no setor das comunicações, notadamente por questões de segurança nacional, propaganda do próprio regime e possibilidades educacionais. O advento das cores colaboraria com esses interesses e proporcionaria outros como um controle maior sobre o setor televisivo, pioneirismo na América do Sul, avanços tecnológicos e incentivo à indústria nacional.

Desde a segunda metade da década de 1960, membros do governo federal discutiam sobre a implementação das cores nas telinhas dos brasileiros. Entretanto, a televisão em cores começou timidamente sua escalada. Apesar do empenho do governo federal, as relações entre quantidade e preço dos televisores em cores, oferta de programas televisivos coloridos e interesse dos anunciantes retardaram as previsões mais otimistas.

Sendo assim, este artigo tem como intento tratar da determinação do regime militar para implantação da televisão em cores no Brasil, de 1966 a 1974, notadamente por meio das páginas dos periódicos de grande circulação no período, como a revista Veja e os jornais O Estado de S. Paulo, Diário de S. Paulo, O Globo e Jornal do Brasil. ${ }^{1}$

\footnotetext{
Vale ressaltar que os estudos históricos ocupados com uma história social da televisão têm avançado na historiografia brasileira nos últimos anos, notadamente ligados ao Núcleo de Pesquisas Interdisciplinares de Mídia e Linguagem (NUPIMIL), criado em 2005, e desde 2014, como Grupo de Pesquisa História e Mídias Eletrônicas (GPHME), credenciado junto ao CNPq, idealizado pelo historiador Áureo Busetto, vinculado à Universidade Estadual Paulista (Unesp), Faculdade de Ciências e Letras de Assis. Dentre eles, destacamos: Em busca da caixa mágica: o Estado Novo e a televisão (2008), Imagens em alta indefinição: produção televisiva nos estudos históricos (2011) e História plugada e antenada: estudos históricos sobre mídias eletrônicas no Brasil (2017), de autoria ou coordenação de Busetto; Por uma televisão cultural-educativa e pública: a TV Cultura de São Paulo, 1960-1974 (2011) e A Fundação Centro Brasileiro de TV Educativa: debates, projetos e práticas à produção e difusão de conteúdos tele-educativos na Ditadura Militar, 1964-1981 (2017), de Eduardo Amando de Barros Filho; Televisão e política: uma história dos canais e redes de TV no Paraná (1954-1985) (2015), de Osmani Ferreira da Costa; Telecurso $2^{\circ}$ Grau: paradigma no ensino pela TV e legitimação política da Rede Globo, 1977-1981 (2011) e Muito além do conhecimento: a TV Educativa na França e no Brasil (2017), de Wellington Amarante Oliveira; A TV Morena em páginas impressas: vestígios do noticiário sobre a chegada da televisão no estado de Mato Grosso (2019) e Integração Nacional por antenas de TV e a transmissão do Jornal Nacional para Cuiabá (1976) (2020), de Edvaldo Correa Sotana. Apesar desse avanço, muitos temas ainda não receberam a devida atenção. Com relação ao surgimento da televisão em cores, apesar de abordada em vários trabalhos ocupados com a televisão brasileira, encontramos apenas uma dissertação de mestrado que se debruça efetivamente sobre o tema, intitulada A cor do milagre: o advento da TV em cores no Brasil do regime militar. Esta pesquisa pauta-se principalmente no ano da implementação das cores, durante o governo Médici, e traz grandes contribuições, principalmente com relação à história da ciência e da tecnologia.
} 
Nos fundamentamos, sobremaneira, pelas orientações oferecidas pelo historiador francês Jean-Noël Jeanneney para a realização de uma história política da televisão, com relação à autonomia da televisão do ponto de vista da influência do poder político. Segundo Jeanneney, devemos levar em consideração o peso do governo na sociedade e a capacidade de ação do Estado sobre a informação televisiva. Os governos podem apresentar em um episódio ou outro e até mesmo em uma série deles, a concessão ou a cessão de benefícios de acordo com suas pretensões. Com isso, podem limitar a independência da televisão e utilizar de suas prerrogativas para o jogo de força relacionado à outorga de canais e à renovação de concessões televisivas (JEANNENEY, 1996).

A escolha dos periódicos pesquisados se justifica pela tiragem e representação para o período abordado, além de suas relações e intenções com o meio televisivo. Os proprietários dos dois jornais cariocas selecionados, Jornal do Brasil e $O$ Globo, obtiveram concessões televisivas, ainda que a do JB não tenha se concretizado com a operação de um canal de televisão. Entretanto, a família Marinho, proprietária de O Globo, além de passar a operar uma emissora de televisão no início do regime militar, avançou para a liderança hegemônica no setor televisivo no mesmo momento em que se implementavam as cores no Brasil.

A família Mesquita, proprietária do paulista O Estado S. Paulo, até onde é sabido, nunca revelou publicamente interesse em operar um canal de televisão ou entrou em disputa por concessão de canal televisivo. Entretanto, cobriu todos os passos do desenvolvimento da televisão no Brasil, tendo entre suas preocupações uma atenção especial com o papel cultural que a televisão pudesse desempenhar. Em contraponto, o Diário de S. Paulo pertencia aos Diários e Emissoras Associados, grupo com interesses diretos no setor da comunicação social e que exerceu um papel hegemônico nos primeiros anos da televisão brasileira. 
Por fim, a revista Veja, pertencente à Editora Abril, participante de concorrência pública para concessão de canal televisivo e editora de material de apoio para cursos televisionados, que se consolidou no período militar como o semanário mais importante do Brasil, notadamente por seu noticiário político.

\section{Mão firme nas telecomunicações}

Um editorial do Jornal do Brasil no início da década de 1970 afirmava que o governo federal liderava, "com mão firme no terreno das comunicações", não medindo esforços para uma televisão comparável “às melhores do mundo" (TV..., 1970b, p. 6). Desde seu início no poder, os militares investiram estrategicamente nas telecomunicações, principalmente por questões de segurança nacional, propaganda do próprio regime e para sanar os déficits educacionais do país. ${ }^{2}$

Antenados nas experiências estadunidense e europeia, o engenheiro João Ferreira Durão, da secretaria geral do Ministério das Comunicações, afirmava existir pressa do governo brasileiro em implantar as transmissões em cores, vislumbrando o pioneirismo na América Latina. ${ }^{3}$ Outra razão, segundo o engenheiro, era o aperfeiçoamento tecnológico derivado da implantação das transmissões em cores. ${ }^{4}$ Com elas, somava-se um fator de segurança nacional,

\footnotetext{
2 A propaganda política do regime militar avançou juntamente com o desenvolvimento da televisão no Brasil. Segundo Fico, a Assessoria Especial de Relações Públicas da Presidência da República (AERP) se valeu da boa receptividade da televisão entre brasileiros, objetivando construir uma imagem positiva da ditadura (FICO, 1997). Ademais, os militares acreditavam que a televisão poderia contribuir para dirimir os déficits educacionais do Brasil, por meio de programas educativos transmitidos por emissoras comerciais e pela criação de emissoras educativas (BARROS FILHO, 2017). O desenvolvimento dos meios de comunicação também serviria para as preocupações dos governos militares relativas à segurança nacional. Segundo Leal Filho (1988), com essa justificativa foram criadas emissoras "em regiões críticas" e "desinteressantes comercialmente", como a TV Nacional, de São Felix do Araguaia e a TV Nacional, de Fernando de Noronha. Vale lembrar, que os objetivos da Doutrina de Segurança Nacional vinculados às telecomunicações eram integração nacional, integridade territorial, preservação dos valores morais e espirituais da nação e paz social (BORGES, 2003).

Apesar das colocações de João Ferreira Durão, na América Latina, o México saiu na frente com relação à televisão em cores, com experiências próprias e com a utilização do sistema estadunidense. Na Argentina, em meados da década de 1960, a televisão em cores também já era pensada com a possibilidade de utilização do sistema francês SECAM, que havia sido escolhido pela delegação argentina na Conferência Internacional de TV em Cores, realizada em Viena. Entretanto, as cores só seriam efetivamente estabelecidas nas telinhas argentinas no final da década de 1970.

${ }^{4}$ Expediente vislumbrado pelo III Reich na década de 1930, buscando um veículo mais eficaz que o rádio para autopromoção e que os avanços tecnológicos televisivos pudessem ter aplicação bélica (BUSETTO, 2007).
} 
pois técnicos brasileiros passariam a trabalhar com avançados equipamentos eletrônicos, fundamentais na fabricação de armas (ENTRE..., 1972, p. 44).

A implantação da televisão em cores no Brasil entrou efetivamente na pauta do governo militar no final de 1966 e início de 1967. Para tanto, foi formada uma comissão técnica ligada ao Conselho Nacional de Telecomunicações (CONTEL) para estudar os sistemas e experiências internacionais sobre o assunto. ${ }^{5}$ Entre os participantes estavam os professores da Escola Politécnica da Universidade de São Paulo, Hélio Vieira, Nelson Zuanela e Ovidio Barradas, e o engenheiro da Telefunken do Brasil, Édson Veiga. Uma das principais preocupações era a escolha de um dos sistemas de cores existentes, o estadunidense NTSC (National Television System Committee), o francês SECAM (Sequential Couleur à Mémoire) ou o alemão PAL (Phase Alternation Line). ${ }^{6}$

Após alguns meses de estudos, aquela comissão encerrou suas atividades entregando o documento TV a cores no Brasil, no dia 7 de março de 1967. Com base nele, o CONTEL elaborou a Resolução n² 20, adotando para o país o sistema PAL, utilizado pela maioria dos países da Europa Ocidental. No entanto, o sistema brasileiro decorreria diretamente do sistema alemão com ligeiras mudanças, seria o PAL-M, onde a letra "M" representa "modificado". Os técnicos brasileiros, além de apresentar as vantagens técnicas, informaram que a Telefunken, detentora da patente do sistema PAL, abriria mão dos seus royalties em benefício do Brasil (AS CORES..., 1971, p. 52).

\footnotetext{
5 O CONTEL foi criado a partir do Código Brasileiro de Telecomunicações de 1962 e seria responsável pela elaboração de um Plano Nacional de Telecomunicações, aprovado no dia 13 de novembro de 1963, propondo a substituição, em cinco anos, da estrutura obsoleta existente até então, por uma nova rede de telecomunicações e a implantação de uma indústria de equipamentos para esse fim (BARROS FILHO, 2017).

${ }^{6}$ O pioneiro nas transmissões regulares em cores foram os Estados Unidos. O padrão utilizado para essas transmissões foi o NTSC (National Television System Committee), oficializado em 1952. Tanto o sistema francês SECAM (Sequential Couleur à Mémoire), patenteado em 1956, quanto o PAL (Phase Alternation Line), em 1963, incorporaram princípios do sistema estadunidense e visaram seu aprimoramento, notadamente com relação à constância do matiz (ou tom) das cores. Em 1966, a União Europeia de Radiodifusão definiu que o padrão alemão seria o adotado na Europa para preto e branco e cores. O sistema foi inaugurado na Alemanha em 25 de agosto de 1967. Quase dois meses antes, em $1^{\circ}$ de julho, a Inglaterra se tornara o primeiro país a adotar o padrão. Holanda e Suíça começaram em 1968 e Áustria, no ano seguinte. Exceções couberam apenas a França, Principado de Mônaco e União Soviética, que optaram pelo Secam (TOSTES, 2013).
} 
Como o Brasil adotou o sistema estadunidense para as transmissões regulares em preto e branco, iniciadas em 1950, seria necessária a adaptação do padrão alemão para as cores. Com o PAL-M os televisores em funcionamento receberiam em preto e branco as emissões coloridas e os televisores coloridos poderiam captar imagens geradas em preto e branco normalmente. Era a busca pela compatibilidade entre o sistema estadunidense adotado para TV em preto e branco e o sistema alemão escolhido para a televisão em cores. ${ }^{7}$

Apesar da oficialização do sistema PAL-M pelo CONTEL, as tentativas para que o sistema adotado fosse o NTSC americano ou o Secam francês não foram poucas. Segundo o Capitão-Engenheiro Alcyone de Almeida Fernandes, professor de TV do Instituto Militar de Engenharia, da PUC da Guanabara, e um dos especialistas consultados pelo CONTEL:

... a França ofereceu ao Brasil cursos de formação de técnicos para o sistema Secam com todas as despesas pagas e o então presidente Costa e Silva, sem o saber, quase inaugura a estação de Itaboraí, da Embratel, em 1969, transmitindo para o país, diretamente, a imagem em cores do sistema americano. À última hora foi instalado um aparelho que converteu o sinal americano em alemão, impedindo que o presidente desrespeitasse as normas de seu próprio Ministério (TV..., 1970a, p. 36).

Apesar da definição do sistema, a implantação das cores seria retardada. Em agosto de 1968, o engenheiro João Aristides Wiltgen, presidente do CONTEL, divulgava em entrevista coletiva, uma portaria assinada pelo ministro das Comunicações, Carlos Simas, determinando que não fosse apreciado pelo CONTEL qualquer pedido de funcionamento de emissoras de televisão em cores até dezembro de 1971. Esse ato normativo autorizava apenas experiências e demonstrações de televisão em cores, quando solicitadas, e sempre precedidas de "campanha esclarecedora ao público". Além disso, permitia o reexame da Resolução $n^{\circ}$ 20, caso surgisse um novo sistema "mais conveniente tecnicamente e economicamente aos interesses do país" (TV..., 1970a, p. 36). 
A possibilidade de reexame da Resolução n² 20 gerou revolta por parte de alguns membros daquela comissão específica criada pelo CONTEL para estudar a implementação da televisão em cores no Brasil. O coronel Álvaro Pedro considerou o adiamento da implementação da televisão em cores no Brasil como fruto da falta de informação e assessoramento do ministro das Comunicações. Analisando as considerações do novo ato normativo, afirmou que não considerava válidos nenhum dos argumentos apresentados e que todos eles foram previstos e estudados minuciosamente pela Comissão, levando em consideração, inclusive, as ponderações da indústria nacional de televisores e das emissoras televisivas. Considerou que, sem esse retardamento, as cores poderiam ser lançadas no final de 1969. Com relação à consideração que a televisão em cores deveria ser estudada com mais cuidado em todos os seus múltiplos aspectos, declarou que não admitia que fosse dado um atestado de incompetência ao grupo de trabalho que estudou a questão (CORONEL..., 1968, p. 4).

Diferentemente do posicionamento de Álvaro Pedro, o engenheiro Walter Bruch, ${ }^{8}$ inventor do sistema alemão, considerava razoável que o Brasil iniciasse as transmissões coloridas somente em 1972. A introdução dessa inovação exigiria “uma preparação muito cuidadosa” (PROVÁVEL..., 1968, p. 18).

As divergências geradas pela assinatura da portaria que atrasaria o início das transmissões televisivas regulares em cores no Brasil geraram uma crise no Ministério das Comunicações, incluindo a possibilidade da demissão do ministro Carlos Simas. Diante disso, o Jornal do Brasil noticiou que o CONTEL havia convocado uma reunião de emergência para reexaminar o tema e decidir definitivamente os critérios que seriam adotados para a implantação das cores no país (PROVÁVEL..., 1968, p. 18).

O presidente do CONTEL admitiu ter sido precipitada a divulgação da portaria assinada pelo Ministro das Comunicações adiando o início das operações da televisão em cores, ponderando: "só não erra quem não trabalha e agora se

\footnotetext{
${ }^{8}$ Walter Bruch veio para o Brasil para assessorar a Rede Globo na transição para as cores. Ele foi operador técnico das câmeras Telefunken na transmissão das Olimpíadas de Berlim, em 1936, primeiro evento televisivo da história. E, durante a $2^{\circ}$ Guerra Mundial fora convocado para construir e operar um circuito fechado de televisão para controlar o lançamento de foguetes (TOSTES, 2013).
} 
deve dar um passo atrás para consertar o que se fez de errado". 9 Aproveitou para desmentir a acusação de que o CONTEL teria se reunido para debater os critérios da implantação da TV em cores no Brasil, pois "esse problema é de inteira competência do Ministro das Comunicações, Sr. Carlos Simas" (SIMAS..., 1968b, p. 11).

Com relação à possibilidade do pedido de demissão de Simas, o gabinete do Ministro afirmou ter recebido com estranheza o noticiário que a aventava, considerando-o destituído de qualquer fundamento. Verdade ou não, o ministro das Comunicações teria voltado atrás em atrasar a televisão em cores "por falta de condições", modificando a portaria após reunião com o presidente do CONTEL e com o coronel Paulo Alves, presidente do Departamento Nacional de Telecomunicações (DENTEL) ${ }^{10}$ (SIMAS..., 1968a, p. 4).

Após um hiato de aproximadamente dois anos, em dezembro de 1970, Higino Corsetti, sucessor de Carlos Simas à frente do Ministério das Comunicações, buscou encerrar as questões que ficaram pendentes por algum tempo com duas assinaturas. Na primeira penada, por meio da Portaria 678, aprovou e elogiou as conclusões do relatório apresentado pela comissão de estudos para a implantação do sistema de TV em cores no país. Com a segunda, por meio da Portaria 679, estabeleceu as primeiras normas de funcionamento e a data de 31 de março de 1972 para o início das transmissões regulares de programas em cores em todo o território nacional. ${ }^{11}$ Previu ainda que as

\footnotetext{
Em 1967, com a criação do Ministério das Comunicações, o CONTEL, criado como órgão autônomo, passou a ser subordinado à jurisdição desse novo órgão. Essa mudança gerou um impasse jurídico legal, pois existia uma farta legislação a respeito das atribuições do CONTEL. Cogitou-se, inclusive, que o Supremo Tribunal Federal ou o Presidente da República desse fim ao conflito de interesse desses órgãos (SIMAS..., 1968b, p. 11).

${ }^{10}$ Em 1963, o Código Brasileiro de Telecomunicações foi regulamentado pelo Decreto n. 52.026, que detalhou a estrutura, atribuições e funcionamento do Conselho Nacional de Telecomunicações (CONTEL) e do Departamento Nacional de Telecomunicações (DENTEL). O DENTEL seria dedicado à fiscalização do funcionamento do sistema de telecomunicações do país (BARROS FILHO, 2017).

11 O "todo território nacional", em muitos casos apenas força de expressão, dessa vez aplicado com maior legitimidade, pois o presidente da República, um dia após a assinatura das duas portarias, inaugurava o tronco de micro-ondas nordeste, ligando Fortaleza ao Rio Grande do Sul no sistema de telecomunicações nacionais. Ainda não integrados ao sistema permaneciam apenas os estados da região amazônica. Mas era prometido para início do próximo ano que eles estariam prontos para receber as imagens prometidas pelas assinaturas do ministro Corsetti. Médici, quando esteve na Amazônia, mostrou-se preocupado com o número reduzido de emissoras de rádio e televisão nacionais e o grande número de estrangeiras captadas na região, solicitando maior rapidez na integração da região amazônica ao sistema nacional de telecomunicações (ESPERE..., 1970, p. 84).
} 
transmissões normais seriam precedidas de um período de preparação de pessoal (engenheiros, técnicos, artistas, programadores e auxiliares) durante todo o ano de 1971 e de uma fase de testes para as emissoras e fábricas de receptores entre janeiro e março de 1972. Até esse prazo ficariam proibidas quaisquer transmissões em cores no Brasil (ESPERE..., 1970, p. 84).

Segundo o Ministro das Comunicações, a Portaria 679 elucidava que o governo almejava preparar convenientemente o lançamento da TV em cores, afastando as improvisações que outras inovações tecnológicas teriam causado no passado. Assegurava que o prazo dado seria suficiente para que as emissoras se aparelhassem adequadamente e para que as fábricas de equipamentos tivessem tempo de examinar suas conveniências para a disputa do mercado. ${ }^{12}$ Ressaltava que somente os aparelhos fabricados no Brasil poderiam receber as novas imagens. Para aqueles que já possuíssem um televisor em cores trazido legal ou ilegalmente do exterior, advertia: "a importação de equipamentos de TV em cores acarretará prejuízos aos seus compradores, que pagarão mais caro pelos televisores e somente conseguirão receber as imagens em branco e preto" (ESPERE..., 1970, p. 84).

Após a assinatura das duas portarias, Corsetti, em entrevista à imprensa, anteviu que os primeiros televisores produzidos no Brasil para as cores não seriam acessíveis a toda população devido ao alto custo. Acrescentou que a importação de televisores era inviável, pois o sistema adotado para as cores era diferente de todos os outros países. Mas, ressaltou que quando a televisão em cores estivesse operando regularmente, os aparelhos comuns receberiam uma imagem em preto e branco "da mais alta qualidade", dando como exemplo a então recente transmissão da Copa do Mundo de 1970, cujas imagens foram geradas em cores e convertidas em preto e branco para o Brasil, apresentando “imagens excelentes" (TV..., 1970c, p. 13).

\footnotetext{
12 Quatro meses antes da assinatura das portarias, Corsetti se reuniu no Rio de Janeiro com diretores das emissoras de televisão e fabricantes de televisores para deliberarem sobre quando seria mais conveniente para a implantação do sistema de TV em cores no Brasil, dado que a Embratel estaria com toda a aparelhagem pronta para o feito (CORSETTI..., 1970, p. 6).
} 
Vale ressaltar que em 1963, antes dos debates oficiais sobre o tema e dos militares assumirem o poder, no dia 7 de maio, tendo como cenário a biblioteca do Palácio da Alvorada, o presidente João Goulart deu por inaugurada a TV em cores no Brasil. A mensagem do presidente foi considerada o primeiro programa em cores produzido no Brasil. Goulart declarou tratar-se "de mais uma iniciativa pioneira, que se incorpora, neste instante, ao acervo de progresso do Brasil e pela qual me congratulo com os diretores da TV Tupi” (PRESIDENTE..., 1963, p. 8). Alguns jornais consideram o feito como o início da televisão em cores no Brasil.

Dias antes, a TV Tupi de São Paulo foi anunciada como a "pioneira em imagem-som, alcance e cor", notadamente pelos veículos dos Diários e Emissoras Associados, também proprietário da TV Tupi.13 Em 3 de maio de 1963, - Diário de S. Paulo estampou em sua primeira página que a emissora teria lançado a televisão em cores no Brasil. Nas páginas seguintes, o jornal retratou a cerimônia de lançamento, realizada no Teatro Tupi. Segundo Edmundo Monteiro, diretor dos Diários e Emissoras Associados, naquele momento, existiam cerca de 400 televisores importados com capacidade para receber transmissões em cores. Quando dez mil desses televisores estivessem em funcionamento, transmissões de estúdio e externas seriam viáveis (CANAL..., 1963, p. 4).

\section{Nossas transmissões foram um sucesso absoluto}

Após o governo militar fixar qual seria o sistema, diretrizes, normas e datas, era a vez das emissoras televisivas e fabricantes de televisores executarem a meta governamental e fazerem a TV em cores se tornar uma realidade no Brasil. Após os estudos da comissão do CONTEL e antes da inauguração oficial marcada para 1972 ocorreram algumas transmissões testes, tanto por iniciativas federais como por parte das emissoras.

Em 1968, a TV Tupi de São Paulo exibiu alguns filmes coloridos com adaptações feitas no equipamento que dispunha. No mesmo ano, também de forma improvisada, a TV Globo transmitiu em cores o Grande Prêmio Brasil e o

\footnotetext{
13 Segundo Xavier e Sacchi, a apresentação foi antecipada por temer que a TV Excelsior conseguisse mostrar a novidade tecnológica primeiro. A TV Excelsior realizou no mesmo ano duas transmissões em cores, em 28 de junho e 31 de julho de 1963 (XAVIER; SACCHI, 2000).
} 
filme nacional Juventude e Ternura. As imagens coloridas só foram captadas pelos raros possuidores de televisores adequados, os demais telespectadores assistiam em branco e preto (A CÔR..., 1970, p. 85).

No ano seguinte, em Brasília, quem estava diante da televisão por volta das 20 horas do dia 7 de agosto, foi surpreendido com as imagens em azul, vermelho e verde de desconhecidas marcas de cigarros e rótulos de cerveja anunciados em inglês. Era a TV Alvorada, canal 8, fazendo a primeira experiência no Brasil do sistema Color Tel. ${ }^{14}$ Essa invenção estadunidense permitia aos televisores preto e branco receberem imagens coloridas sem sofrer adaptação (COMERCIAIS..., 1969, p. 60). ${ }^{15}$

Em 1970, embora ainda não possuíssem câmeras para produzir programas televisivos em cores, Globo e Tupi estavam preparadas para receber e transmitir sinais em cores da Copa do Mundo de 1970, vindas do México (O FUTURO..., 1970, p. 52). Nesse período foi comum a divulgação de imagens do presidente Médici acompanhando os jogos televisionados em cores, notadamente da final vencida pelo Brasil (AS IMAGENS..., 1970, p. 72).

Após a Copa do Mundo, buscou-se intensificar os esforços para implantação das cores em definitivo. O governo promoveu diversas reuniões com fabricantes de televisores e representantes das emissoras televisivas. Por meio de estímulos federais, a Rede Globo estava importando equipamentos estadunidenses e alemães para produção e transmissão em cores. Em outubro de 1970, ela foi a responsável pela primeira transmissão internacional em cores via Intelsat, do Brasil para a América Latina e Europa, exibindo o V Festival Internacional da Canção (AS IMAGENS..., 1970, p. 72).

O primeiro teste oficial da televisão em cores no Brasil foi a transmissão da Festa da Uva de Caxias do Sul, encabeçado pela TV Difusora, canal 10, de Porto

\footnotetext{
4 O sistema Color Tel, que custou dez anos de pesquisa ao inventor estadunidense James Butterfield, baseava-se em estímulos luminosos que só o olho humano percebe. A variação de intensidade desses estímulos dava a ilusão de cor. Uma câmera fotográfica diante do televisor não conseguiria captar as cores (COMERCIAIS..., 1969, p. 60).

15 A empresa Alton Promoções, que representava o sistema Color Tel no Brasil, buscava estrategicamente aguçar o principal mercado televisivo do país, o eixo Rio-São Paulo, para onde prometia fazer um grande lançamento, incluindo vídeos comerciais coloridos de produtos brasileiros (COMERCIAIS..., 1969, p. 60).
} 
Alegre. Inicialmente, o primeiro teste seria a transmissão do carnaval carioca, mas foi cancelado pelo ministro das Comunicações, Higino Corsetti, gaúcho de Caxias do Sul (TV..., 1972, p. 3).

Por ter sido concebida em meio às iniciativas e debates para a televisão em cores no Brasil, a TV Difusora, canal 10 de Porto Alegre, desde sua inauguração, em 10 de outubro de 1969, já possuía equipamentos para transmissão em cores (TELEVISÃO..., 1972, p. 6).

Na manhã do dia 20 de janeiro de 1972, o presidente Garrastazu Médici inaugurou a Festa da Uva com transmissão em cores pela televisão. A realização desse evento esteve ameaçada até o último momento em função das chuvas que acompanharam Médici por toda sua estada no sul do país (MÉDICl..., 1972, p. 3).

Apesar de ter sido testemunhada por cerca de quinhentos televisores, a TV Difusora de Porto Alegre classificou sua transmissão como "extraordinária", "sensacional", "feito histórico". Afinal, como era o primeiro teste oficial, o que importava não era a audiência, mas a aprovação da Embratel e o fato de a emissora realizar seu sonho pioneirista (PIONEIRISMOS..., 1972, p. 69).

Segundo Valério de Andrade, responsável pela coluna Televisão do Jornal do Brasil, apesar de muita gente ainda duvidar que o prazo limite estipulado pelo governo para a televisão em cores fosse cumprido, com a transmissão da Copa do Mundo, V Festival da Canção e da Festa da Uva, o Brasil ingressava oficialmente na era das cores, assinalando um novo marco no campo das telecomunicações e vencendo a disputa com os demais países da América do Sul. Segundo o colunista, salvo pequeno número de privilegiados possuidores de televisores capazes de receber imagens coloridas, a maior parte dos cariocas que assistiram o primeiro teste oficial conquistaram arduamente lugares nas calçadas ou dentro das lojas de eletrodomésticos, exclamando: "Parece Cinema" (ANDRADE, 1972, 57).

Para a inauguração oficial da TV em cores no Brasil, o ministro das Comunicações vislumbrava a transmissão de uma mesma programação por todas emissoras do país. As que não possuíssem condições para tanto, poderiam 
integrar a rede nacional da mesma maneira, transmitindo os programas em preto e branco (CORSETTI..., 1972, p. 22).

Poucos dias antes da inauguração oficial da televisão em cores ocorreu um fato curioso. O arcebispo de São Paulo, Dom Evaristo Arns, procurou o Ministério das Comunicações e as emissoras de televisão para questionar se não estariam esquecendo que o dia 31 de março era "sexta-feira da paixão". Provavelmente o governo não se atentou para esse fato ou não o achou significativo a ponto de mudar a data, pois o objetivo principal era que coincidisse com o "aniversário da revolução". Mas o alerta do arcebispo foi ouvido e fez com que a programação inaugural sofresse adequações. Os festejos do aniversário da "revolução" foram adiados para $1^{\circ}$ de abril (CORES..., 1972, p. 76).

Além de questões religiosas, questões técnicas ameaçavam o brilho da inauguração da televisão em cores no Brasil. Situação que levou o ministro das Comunicações a se reunir com os representantes das emissoras televisivas e decidirem que a programação inaugural ficaria reduzida a um discurso do presidente Médici, um filme sobre o Brasil e transmissão de um ato religioso (CORES..., 1972, p. 76).

Com exceção do filme sobre o Brasil, de 54 minutos, produzidos há tempos por Jean Manzon, sob encomenda da Volkswagen, as outas duas partes da programação ofereciam dificuldades. Para a transmissão da "Paixão de Cristo", como foi sugerido na reunião, seria necessário deslocar um caminhão de externas para Nova Jerusalém, em Pernambuco, ou Tubarão, em Santa Catarina, onde tradicionalmente eram feitas encenações públicas. Mas o único caminhão de externas em condições de operar no dia 31 de março era o da TV Rio, o mesmo do primeiro teste em Caxias do Sul, na Festa da Uva, e seria usado para transmitir a fala presidencial. Parte essa que aparentava ser a mais simples da programação, segundo o Ministério das Comunicações, também enfrentava dificuldades. No Palácio das Laranjeiras, no Rio de Janeiro, temia-se que surgissem problemas de iluminação, peça fundamental para transmissões em cores e para os quais os técnicos brasileiros ainda não estariam preparados (CORES..., 1972, p. 76). 
Enfim, entre desconfianças e otimismos, com os improvisos costumeiros, a televisão em cores foi inaugurada oficialmente na data pré-determinada, 31 de março de 1972, "sexta-feira da paixão". Expressões de autoelogios, como: "entramos numa nova e grandiosa era", "nossas transmissões foram um sucesso absoluto", "fomos mais uma vez pioneiros", “... e agora vamos dar um banho de cores no mundo", entre outras, atingiram o restrito número de telespectadores capazes de receber e avaliar a transmissão colorida. Segundo os fabricantes, havia cerca de 5 mil aparelhos televisivos em funcionamento naquele dia (A TV..., 1972, p. 78).

Segundo a descrição da revista Veja, as reações desse público seleto provavelmente oscilaram entre estupefação e confusão. O que apareceu em suas telinhas não sugeriria tanta confiança. O ministro das Comunicações, coronel Hygino Corsetti, ao abrir com um discurso curto a programação inaugural, transmitida em rede encabeçada pela Globo do Rio de Janeiro, aparecia nitidamente, embora com a cor da pele puxada para o vermelho. Ao fundo, em um painel com figuras geométricas, as cores estavam difusas, com predominância do azul. Na atração seguinte, um velho filme americano cedido pela Cúria Metropolitana da Guanabara, sobre a vida de Cristo, alguns trechos apareceram perfeitos, mas logo as cores voltaram a ficar esmaecidas ou borradas. Na produção de Jean Mazon, Viagem pelo Brasil, o vermelho invadiu tudo, embora as imagens fossem nítidas (A TV..., 1972, p. 78).

Os telespectadores que acompanharam a programação inaugural e que prestaram depoimento a revista Veja entenderam as imperfeições e aprovaram as transmissões. Um deles, de 63 anos, afirmou ter deixado de comprar um carro para ter seu televisor em cores e não se arrependia, apesar de ter sido obrigado a levantar muitas vezes da poltrona para tentar dar mais nitidez às imagens. Acreditava que as imagens melhorariam com o tempo. Além disso, esbanjava que o televisor colorido the dava prestígio entre seus vizinhos da vila de sobradinhos geminados onde morava, com a mulher, no bairro do Itaim, em São Paulo. Eles encheriam sua sala durante as transmissões em cores. Era o resgate dos "televizinhos", figuras que a popularização da TV em preto e branco extinguiu e a colorida, acessível a poucos, estava resgatando (A TV..., 1972, p. 78). 
Nem a pressa do governo, nem as preocupações dos fabricantes e concessionários televisivos estiveram presentes na festa da inauguração. Os adjetivos bombásticos dos locutores fizeram um pitoresco contraponto às deficiências resultantes da improvisação. A televisão em cores estreou oficialmente em terras brasileiras, mais como uma promessa do que um sistema consolidado. Entre reprises e momentos de cores mal reguladas, os momentos de boas imagens mostravam que a qualidade das transmissões poderia atingir níveis melhores, à medida que problemas naturais, como ajuste de câmeras e iluminação, fossem superados. Entre o que se ouvia e o que se via, sobrava certamente bastante assunto para os orgulhosos proprietários de televisores em cores e seus curiosos televizinhos. Com os preços apresentados incialmente, o televisor colorido era sinônimo de status social.

\section{Diversão da elite}

"Que venha logo a TV em cores... as elites estão sempre precisando de novas diversões", exclamava Abelardo Barbosa, o Chacrinha. Os brasileiros privilegiados, reunidos na sede paulista da Embratel veriam as camisas verdes dos jogadores mexicanos de futebol e as camisas vermelhas de seus adversários russos, no primeiro jogo da Copa do Mundo de 1970. Na mesma hora, pelo menos 20 milhões de brasileiros comuns, ao redor dos 5 milhões de aparelhos de TV, recomeçariam a exercitar seus olhos na difícil tarefa de sempre: distinguir, em tons de cinza, o que é verde e o que é vermelho. Eram os telespectadores do branco e preto. A maior parte deles nunca tinham visto a TV em cores e estavam de tal maneira distantes dela, que um terço deles, segundo pesquisas de 1969 da Gallup e da Fundação Armando Álvares Penteado, ainda nem sabia que ela havia sido inventada (TV..., 1970a, p. 36).

Após a escolha do sistema para televisão em cores, o governo brasileiro buscou segurar a inovação até que houvesse condições de mercado para sua difusão. Em seu pronunciamento de 1970, o Ministro das Comunicações evidenciava que a posição adotada pelo governo militar era a de cautela para a implementação das cores no Brasil. Segundo Corsetti, não se podia "perder de vista que a realidade da TV brasileira envolve três elos de uma só corrente: o 
fabricante de aparelhos de TV, cujos lucros aumentam em ritmo pequeno; o mercado consumidor, que cresceu em progressão lenta; e as estações de TV, algumas delas precisando se recompor de crises" (TV..., 1970a, p. 36).

Embora os troncos da Embratel já estivessem aparelhados para transmissão em cores, situação que, conforme o ministro, teria ficado provada durante as transmissões da Copa do Mundo de Futebol de 1970, seria necessário um certo tempo para que as emissoras televisivas e os fabricantes de televisores tivessem condições de implantar definitivamente a TV em cores no Brasil (GOVERNO..., 1970, p. 4).

Corsetti, em maio 1970, prometia que o governo militar procuraria medidas para facilitar a aquisição de televisores, propondo a formação de um grupo de trabalho para estudar o assunto por noventa dias. Entendia ser necessário fortalecer a indústria nacional de televisores, mas sem subvenção governamental. Finalizando: "Não há urgência na implantação da TV colorida, mas preparem-se para recebê-la" (GOVERNO..., 1970, p. 4).

Conforme abordado anteriormente, a escolha do PAL-M visou, entre outras coisas, privilegiar a indústria nacional de televisores. Os técnicos da Embratel explicavam que se o Brasil adotasse o NTSC estadunidense ou o Secam francês ou mesmo o PAL alemão, as demandas do mercado nacional seriam supridas por televisores importados. Ademais, acreditava-se que outros países da América Latina adotariam o mesmo sistema, o que permitiria a venda do excedente da produção nacional (AS CORES..., 1971, p. 52).

O ministro das Comunicações achava que o espírito de competição natural entre os fabricantes de televisores, na fase de lançamento do sistema em cores, deveria revestir-se das virtudes da cautela. Dos apontamentos do governo teria nascido o acordo cavalheiresco entre os fabricantes de televisores, mesmo estando quase todos com seus modelos para televisão em cores passando por testes finais de laboratório. Segundo Olinto Rizzo, presidente da Associação dos Fabricantes de Rádios, Televisores e Eletrônica (AFRATE), "as fábricas comprometeram-se a só começarem a produção em série de seus aparelhos no primeiro semestre de 1972" (RIZZO, 1970 apud TV..., 1970a, p. 36). Para qualquer uma delas, sair com seu modelo em cor antes das concorrentes não 
compensaria o negativo do mercado dos televisores em preto e branco. As fábricas produziam cerca de quatrocentos desses televisores por dia e temiam ficar com os depósitos abarrotados. Os fabricantes de televisores temiam causar o mesmo desastre criado pela estreia da TV em cores no México, em 1968, onde as vendas do branco e preto caíram imediatamente 35\% (TV..., 1970a, p. 36).

Apostava-se que a Telefunken despontaria entre os fabricantes para o mercado brasileiro. Pois, apesar da participação secundária no mercado preto e branco do país, foi nos seus laboratórios na Alemanha que nasceu o sistema escolhido pelo Brasil. Dizia Ernani Bessa, secretário geral da AFRATE: "a Telefunken está ansiosa para conquistar o consumidor classe A, que, com a colocação da TV em cores no mercado, desprezaria o branco e preto" (TV..., 1970a, p. 36).

Os fabricantes de receptores estariam interessados em abrir uma nova faixa no mercado de televisores, que nos grandes centros chegava a quase 90\% de saturação. Em 1971, calculava-se uma retração de 30\% nas vendas de preto e branco. Os empresários do setor estavam cientes que iam desbravar essa nova faixa e que a tarefa exigia paciência, principalmente por causa do preço do televisor, em decorrência da maioria dos componentes utilizados para sua fabricação serem importados. Ainda assim, estavam otimistas. Rodolfo Heitmann, do departamento de divulgação da Telefunken, explicava que o mercado, apesar de pequeno, era valioso. "É uma questão matemática: em vez de vender mil aparelhos comuns, basta vender duzentos em cores" (TV..., 1970a, p. 36).

Cinco fábricas se preparavam para lançar televisores coloridos no Brasil, prometiam uma produção inicial de 10 mil unidades, todos do mesmo tipo, com 26 polegadas e custando por volta de 6 mil cruzeiros, além de um modelo "mais popular" que entraria no mercado em 1973 com um custo menor para o consumidor (CORSETTI..., 1971b, p. 26).

Os primeiros aparelhos em cores postos à venda pesavam cerca de $50 \mathrm{Kg}$, 70\% a mais do que os convencionais, além de maiores. Dificilmente eram suportados por mesas convencionais, fato que levou os televisores com console a serem mais vendidos inicialmente. Os primeiros televisores coloridos eram 
muito sensíveis e requeriam uma série de cuidados para que não fossem danificados (COMPRADORES..., 1972, p. 14).

A previsão inicial era que os primeiros televisores em cores fossem entregues para os lojistas em janeiro de 1972. As grandes lojas cariocas de eletrodomésticos vendiam uma média mensal de 25 mil televisores em preto e branco e calculavam que, inicialmente, as vendas de televisores em cores não ultrapassariam os 8 mil mensais. Existiam cerca de 6 milhões de televisores em preto e branco em funcionamento no Brasil, aproximadamente 3 milhões em São Paulo e quase 2 milhões no Rio de Janeiro. Inicialmente os televisores coloridos representariam uma fração ínfima em relação aos aparelhos comuns, gerando receio por parte das emissoras e patrocinadores (FÁBRICAS..., 1972a, p. 14).

Além da relativa diminuta produção de televisores coloridos, o preço também se apresentava como um fator limitador. Diferentemente dos 6 mil cruzeiros prometidos pelos fabricantes, o televisor da Admiral-Springer começou custando cerca de 8 mil cruzeiros. Os modelos da Phillips e da Telefunken eram anunciados em algumas lojas por 9 mil e 500 cruzeiros (COMÉRCIO..., 1972, p. 28).

O custo dos televisores acima do acordado gerou descontentamento no Ministério das Comunicações, que, apesar de não poder decidir diretamente sobre a fixação dos preços, tarefa que competia exclusivamente à Comissão Interministerial de Preços, continuaria insistindo junto aos fabricantes para que diminuíssem os valores para garantir o êxito da implantação do sistema em cores no Brasil (FÁBRICAS..., 1972b, p. 26).

De acordo com uma pesquisa feita em 1970 pelo Instituto Gallup, 31\% das pessoas se diziam dispostas a trocar seu televisor em preto e branco por um em cores. Porém, ao responder, o entrevistado estava supondo um preço por aparelho três vezes maior que o comum, segundo indicação que acompanhava a pergunta, e que toda programação das emissoras de televisão seria em cores (A IMATURA..., 1971, p. 84).

Em fevereiro de 1972 foram vendidos pouco mais de 3,5 mil aparelhos, correspondendo às previsões dos fabricantes. No mês seguinte, momento em que o ministro das Comunicações passou a fazer declarações mais incisivas 
contra os preços altos dos televisores coloridos, as vendas não chegaram a 2 mil aparelhos. Agravando esse quadro, algumas fábricas estavam recebendo pedidos de cancelamento de encomendas de revendedores, que decidiram esperar a baixa no preço (A TV..., 1972, p. 78).

Segundo os fabricantes, essa redução nos custos seria impossível a curto prazo. O modelo de mesa, mais barato, saia para o revendedor por 3 mil e 800 cruzeiros, sendo que 60\% desse preço correspondia a componentes importados, apenas o cinescópio custava 1 mil e 200 cruzeiros. Acrescidos de $20 \%$ do imposto sobre produtos industrializados e 17\% de ICM, mais o lucro da loja, cada aparelho chegava às vitrines por, no mínimo 7 mil cruzeiros. Nos EUA, em 1953, quando começou a TV em cores, um receptor custava o equivalente a 4 mil 800 e 6 mil cruzeiros, e a implantação do sistema vinha sendo conseguida aos poucos. No mesmo momento, no início da década de 1970, existiam 50 milhões de aparelhos em cores nos lares estadunidenses, para 150 milhões em preto e branco (A TV..., 1972, p. 78).

Entre as alternativas aos altos preços dos primeiros televisores para as cores, apresentava-se a formação de consórcios, semelhantes aos que eram feitos para os automóveis. Em São Paulo, havia anúncios de consórcios que reuniam geralmente grupos de cem pessoas e prometiam o sorteio de até quinze televisores coloridos por mês (A IMATURA..., 1971, p. 84).

Ary Braga, coordenador do sistema de fiscalização da Secretaria da Receita em Brasília, afirmava que não pretendia proibir ou dificultar os consórcios, mas "não podemos permitir que eles se transformem em sinônimo de arapuca e prejudiquem a economia popular". A Secretaria teria recebido denúncias de alguns consórcios que ofereciam televisores entre 4 e 5 mil cruzeiros apenas para atrair participantes, aumentando depois o preço para entre 7 e 8 mil cruzeiros. Os técnicos do Ministério da Fazenda preparavam uma regulamentação visando extinguir esse tipo de problema. Entretanto, conforme teria afirmado o gerente de uma loja paulistana de televisores: "enquanto perdurar essa confusão não poderemos ter esperanças de muitas vendas, pois a maioria das pessoas está ficando com medo de ser lograda" (PIONEIRISMOS..., 1972, p. 69). 
Outra alternativa apresentada no período era o aluguel de aparelhos em cores. Era comum os periódicos de grande circulação veicularem anúncios de empresas que alugavam televisores. Conforme os anunciantes, devido ao alto custo dos televisores, a opção pelo aluguel poderia representar economia, tranquilidade, atualidade e liberdade. Economia, pois era possível alugar por dia ou por mês, sem juros ou empate de capital. Tranquilidade, pois as empresas prometiam arcar com os custos de possíveis consertos nos aparelhos alugados e ainda se responsabilizavam em emprestar um outro televisor durante o período de reparo. Atualidade devido à possibilidade dos televisores serem trocados, por um novo, anualmente. E liberdade, pois os locatários não ficariam presos a televisores obsoletos, poderiam interromper a locação em qualquer momento e ainda poderiam adquirir um televisor tendo como desconto o valor das parcelas pagas como aluguel. As empresas locadoras de aparelhos ainda se responsabilizavam pela instalação dos televisores (TV..., 1973, p. 14).

De um modo geral, o entusiasmo gerado pela chegada das cores vinha acompanhado da mais absoluta falta de informação. Além do preço, poucos sabiam inicialmente que a programação colorida seria escassa e que somente em meados de 1974 haveria as condições de produzir com regularidade programas em cor no Brasil.

Os gerentes das lojas de eletrodomésticos achavam que a venda de aparelhos em cores não seria muito fácil, pois, além do preço, as emissoras televisivas já haviam anunciado que a programação colorida se limitaria basicamente na transmissão de filmes durante o primeiro ano de atividade das cores. Ademais, programação colorida ocuparia horários em que as lojas já estariam fechadas. A TV Globo anunciava sua programação em cores a partir das 22 horas, impedindo que as lojas mostrassem aos consumidores programas em cores (COMÉRCIO..., 1972, p. 28).

O diretor comercial da Philco, Adalberto Machado, atrelava a venda de aparelhos à quantidade de programas coloridos que as emissoras transmitiriam, pois o otimismo do público mudaria quando percebessem que um televisor em cores "é apenas um receptor de preto e branco de luxo". E, finalizou: "Por 
enquanto estamos vendendo espingardas, mas falta munição na praça" (ESTOQUE..., 1972, p. 55).

\section{Mais vale um Ibope em preto e branco do que um fracasso colorido}

Cerca de um ano antes da inauguração oficial das transmissões em cores, havia eufóricos e temerosos com a novidade. Não se sabia muito bem qual seriam os resultados. Alguns dirigentes das emissoras de televisão, quando pensavam friamente, em termos financeiros, chegavam a previsões sombrias, tendo em vista os pesados investimentos e a infinidade de problemas técnicos e humanos das emissoras para se equiparem.

Os diretores das emissoras de televisão não negavam que seria melhor esperar mais alguns anos. Wilson da Silveira Brito, engenheiro eletrônico da TV Globo, via a TV colorida como um "fantasma". Acha que talvez em 1975 ou 1976 fosse o momento ideal para sua implementação. Essa opinião também era compartilhada por João Saad, então presidente da Associação Brasileira de Emissoras de Rádio e TV (ABERT): "Nós ainda não atingimos um bom nível em preto e branco e já vamos passar para a cor. Além disso, há emissoras que ainda nem acabaram de pagar os seus equipamentos para o preto e branco" (A IMATURA..., 1971, p. 84).

Outros, entretanto, talvez fiéis aos princípios seguidos desde o início do meio televisivo no Brasil de que para todos os problemas há um jeitinho, aproximavam-se do otimismo. "Vai ser como foi no começo em 1950: a gente apanha um pouco, mas logo depois tudo engrena e vai para a frente", dizia Cassiano Gabus Mendes, diretor da Tupi de São Paulo e um dos pioneiros da TV no Brasil (A IMATURA..., 1971, p. 84).

A revista Veja, em sua coluna sobre televisão, previa que o mais provável era que a situação se definiria pelo meio termo e a cor funcionaria como um elemento seletivo, permitindo a sobrevivência apenas dos mais capazes ou dos mais ricos (A IMATURA..., 1971, p. 84).

Temerosos, confiando na sorte e pressionadas pelo governo federal, a maioria das emissoras televisivas brasileiras se preparavam para as cores. 
Movimentavam-se para mandar seus técnicos ao exterior e negociavam a importação de equipamentos. No início, as cores seriam servidas em doses mínimas, pois para transmitir toda a sua programação em cores, uma emissora precisaria gastar cerca de 1,5 milhão de dólares em equipamentos (A IMATURA..., 1971, p. 84).

Os agentes das emissoras televisivas avaliavam que doses mais generosas de cor dependeriam de um maior número de televisores coloridos no mercado, embora já existissem alguns possíveis anunciantes, como Coca-Cola e a Esso, que tinham filmes publicitários coloridos feitos no exterior, e a Nestlé, que estava produzindo alguns no Brasil. Wilson Brito, da TV Globo, afirmava que, enquanto os receptores para a cor não representassem pelo menos $20 \%$ do total, e isso levaria dois ou três anos, não seria possível comercializar a TV colorida e o dinheiro investido não renderia nada. Ninguém iria querer pagar um preço maior se a maioria dos telespectadores iria assistir o anúncio em preto e branco (A IMATURA..., 1971, p. 84).

Aparentemente havia um dilema entre emissoras e fabricantes de televisores. Como mencionado no tópico anterior, os fabricantes avaliavam que só poderiam avançar quando as emissoras transmitissem um número significativo de programas coloridos. Ao mesmo tempo, os representantes das emissoras pediam a elevação da produção de televisores para que fosse viável investir em produções em cores.

O ministro Higino Corsetti propunha que fabricantes e emissoras entrassem num acordo. Os fabricantes planejavam para três anos seguidos, a partir de 1972, 100 mil aparelhos no primeiro ano, mais 100 mil no segundo e 250 mil no terceiro, totalizando 450 mil, o que representava menos de 10\% do número de aparelhos convencionais que recebiam imagens em preto e branco. Do outro lado da mesa, as emissoras entendiam que eram necessários pelo menos um milhão de televisores para as cores naqueles três anos para atrair o interesse dos anunciantes e a televisão em cores se tornar uma realidade (TV..., 1971, p. 8).

Às vésperas do lançamento da televisão em cores no Brasil, o ministro das Comunicações foi questionado, em entrevista à revista Veja, se estava otimista, pois ainda havia preocupação sobre a capacidade da maioria das emissoras de 
incorporar essa tecnologia. Em resposta, Corsetti afirmou que a tendência era a consolidação de três redes nacionais, formadas por emissoras próprias ou independentes, associadas e com liberdade para trocarem de programação conforme as conveniências. Acreditava que essas redes se firmariam ajustando sua administração e vencendo suas dificuldades técnicas, econômicas e financeiras. Segundo Corsetti, três redes nacionais seriam "suficientes para diversificar a programação e oferecer opções ao público" (ENTRE..., 1972, p. 44).

Segundo o Ministro da Comunicações, a implantação das cores seria um dos fatores de influência para a melhoria "da qualidade da programação" televisiva, uma preocupação constante no governo Médici, pois: "Por custar mais caro, a transmissão a cores não permitirá que se empregue um numerário em programações falhas, de mau gosto" (CORSETTI..., 1971a, p. 13).

Passado o entusiasmo inaugural, a televisão em cores teria de se curvar ante uma realidade rigorosa: a produção dos programas era aproximadamente 30\% mais cara e não seria possível conseguir patrocínios enquanto os aparelhos em funcionamento não fossem em número expressivo. A base da programação em cores, no início, seriam filmes e seriados que, em sua maioria, eram velhos conhecidos dos telespectadores, além de algumas transmissões esportivas e esporádicos "grandes eventos". Os programas de maior audiência, como os de auditório apresentados por Chacrinha e Silvio Santos, e as telenovelas, continuariam sendo produzidos e transmitidos em preto e branco (ATV..., 1972, p. 78).

A TV Globo anunciava nos veículos impressos que "os melhores programas da TV continuarão em preto e branco":

Você pode achar estranho ouvir isso da Rede Globo, líder absoluta no Brasil. Não quer dizer que não vamos fazer TV a cores. Claro que vamos. Na data histórica de 31 de março, escolhida pelo Ministério das Comunicações, entraremos no ar a cores. Três dias por semana, no mínimo. Após às 22:45. Com filmes - caminho correto para fase inicial da cor na TV. Eventualmente, um grande acontecimento esportivo ou artístico, poderá merecer uma transmissão especial a cores durante 1972. O comportamento da Rede Globo neste ano, é decorrente das recomendações do Ministro das Comunicações, sobre o cuidadoso planejamento que as emissoras devem seguir na implantação da cor. E da nossa 
responsabilidade que temos diante de nosso público, acostumado a reconhecer o 'PADRÃO GLOBO DE QUALIDADE'. A cor exige, ainda, muito mais. Por isso, nossos técnicos formados no exterior, continuam a desenvolver o programa de treinamento e aperfeiçoamento de todas as equipes, para darem a você o 'PADRÃO GLOBO DE QUALIDADE A CORES'. Enquanto isso, continuamos a produzir em 72, a melhor televisão do país para os atuais 8 milhões de aparelhos, que só receberão imagem em preto e branco (e quem tiver aparelhos a cores receberá, também, a mesma imagem em preto e branco). Seja como for - em cores ou em preto e branco - líder absoluta no Brasil (PIONEIRISMOS..., 1972, p. 69).

Em outubro de 1972, a TV Tupi de São Paulo anunciava com eloquência o lançamento da primeira telenovela em cores da televisão brasileira. Mas, quando A Revolta dos Anjos foi ao ar, no início do mês seguinte, os telespectadores constataram que seus ídolos continuavam tão cinzentos quanto antes. O equipamento especial para gravação em cores não havia chegado e a emissora resolveu gravar a novela com o que tinha à mão. A TV Tupi prometia mudar o sistema assim que chegassem os novos equipamentos, criando um suspense sobre em qual momento a novela se coloriria (A NOVELA..., 1972, p. 94).

No mesmo momento, a Rede Globo começava a gravar em cores, em Salvador, os primeiros capítulos da novela O Bem Amado. Mas os raros proprietários de receptores coloridos teriam ainda que esperar mais um pouco. A novela só seria exibida em cores para os técnicos da própria emissora, visando o aperfeiçoamento das produções. A Globo redobrou os cuidados em relação ao uso das cores nas telenovelas, os mais rentáveis carros-chefes de sua programação. Conforme explicava Daniel Filho, coordenador da central de novelas da emissora, "a Globo preza muito os altos índices do IBOPE conseguidos com a programação em preto e branco e não pretende se aventurar em um terreno ainda pouco conhecido" (A NOVELA..., 1972, p. 94).

Na primeira semana de experiência, a Rede Globo já havia comprovado duas diferenças importantes entre os dois processos de filmagens, em cores e preto e branco, que a gravação e o acabamento em cores exigiam muito mais cuidado e levavam o dobro do tempo para serem executados. Segundo Daniel Filho, as cores requeriam uma movimentação de câmeras muito mais precisa e planejada, com ensaios mais cuidadosos, interiores mais cuidados e escolha de 
exteriores "feita a dedo, pois qualquer imperfeição não passa despercebida como no preto e branco". A média de gravação de seis capítulos em três dias, conseguida com o preto e branco, caia para metade, quando colorida. Por fim, Daniel filho afirmou que o teste com as gravações de 0 bem amado era para saber se uma telenovela em cores já seria economicamente viável, pois "mais vale um Ibope em preto e branco do que um fracasso colorido" (A NOVELA..., 1972, p. 94).

Lentamente a programação em cores foi avançando e alcançando espaço nas grades das emissoras televisivas. As emissoras de maiores audiências passaram a ser pressionadas pela ânsia das emissoras menores em conquistar audiência com programas em cores. Algumas emissoras televisivas viram nas cores uma oportunidade de aumentar suas respectivas audiências. A TV Bandeirantes, de São Paulo, foi a principal responsável por essa política de apressamento das cores. João Saad não concordava com a linha da Globo, "para nós, a implantação foi benéfica e não temos a menor intenção de reduzir o volume de nossa programação colorida". A média de audiência da TV Bandeirantes que era invariavelmente inferior aos 5\%, com programas em branco e preto, em 1974, com sua programação basicamente coloria - mais de 70\% do total, média mais alta entre todas as emissoras televisivas brasileiras - chegava a dar picos de 12\% a 15\% (EXPLOSÃO..., 1974, p. 86).

Essa "euforia colorida", argumentava representantes da Globo e Tupi, custava muito caro relativamente ao número de telespectadores alcançados. Segundo eles, além da produção ser mais cara, a publicidade colorida rendia apenas 20\% a mais que a preta e branca. Edvaldo Pacote, da Globo, asseverava que a tendência seria de estagnação no processo de aumento no volume de horas de programas em cores em relação aos em branco e preto. Seriam necessários ao menos um milhão de televisores em cores em funcionamento para acelerar a programação colorida. Na mesma direção, Rubens Furtado, da Tupi, afirmava serem necessários mais de 2 milhões de televisores compatíveis para que a totalidade da programação da emissora fosse colorida (EXPLOSÃO..., 1974, p. 86). 
Em 1974, havia por volta de 400 mil televisores coloridos em funcionamento, contra cerca de 10 milhões de televisores em preto e branco. As emissoras queriam mais televisores em cores em funcionamento para aumentarem sua programação, pois atrairia anunciantes. A produção colorida era ao menos três vezes mais cara que a em preto e branco, além disso muitas das emissoras precisavam pagar as parcelas dos financiamentos feitos para aquisição de recursos tecnológicos. Por outro lado, a indústria de televisores afirmava que com o aumento da programação em cores a procura por televisores seria maior, consequentemente poriam mais televisores no mercado a um preço menor. E, o governo federal tentava solucionar o impasse e estabelecer as cores em definitivo.

\section{Considerações Finais}

A implantação da televisão em cores no Brasil foi uma medida da ditadura militar. Apesar de improvisos e alguns passos mal planejados, o governo não mediu esforços para essa implantação. A data escolhida para sua estreia é um bom exemplo da importância dada para esse evento. Apesar da dificuldade de um equilíbrio entre a produção colorida, fabricação de televisores e anunciantes, a televisão em cores foi ganhando seu espaço e se consolidando. O advento das cores traria benefícios para o Brasil, como, em função da escolha do modelo PAL-M, o estímulo à indústria nacional de televisores, sem a concorrência dos televisores importados.

Mais que benefícios para o Brasil, as cores contribuiriam significativamente para o regime militar. O pioneirismo do Brasil na América do Sul daria visibilidade para o governo militar. O avanço das telecomunicações era estratégico para uma ditadura, por questões de segurança nacional e de inculcação ideológica do próprio regime. Nada mais racional que investir e aumentar a atratividade de um meio que se consolidaria como a maior fonte de informação pela maioria da população.

O advento das cores serviria também para um controle maior do setor televisivo. Isso ocorreria de duas formas principais. Para as cores eram necessários investimentos e nem todas as emissoras estariam em condições 
para tanto. Mas, conforme as palavras do próprio ministro das Comunicações, isso não seria um problema. A consolidação de três redes nacionais seria suficiente. Fato que, obviamente, facilitaria a fiscalização e censura dos conteúdos transmitidos. Vale ressaltar também que, as três possíveis redes que sobreviveriam já estavam miradas pelo governo, caso mais evidente é o da Rede Globo. Assim como, com sinal trocado, a TV Excelsior, sufocada até o seu fim pela ditadura (BUSETO, 2009).

A segunda maneira de controle era, como a produção em cores era mais custosa, o ministro acreditava que não gastariam dinheiro com programas "popularescos" ou considerados de "baixo nível", preocupação dos governos militares, principalmente do período Médici. Talvez querendo dizer que não gastariam recursos com programas que pudessem ser censurados, ou seja, as cores potencializariam a autocensura, e alinhariam ainda mais as emissoras sobreviventes ao regime militar.

Nada mais interessante para uma ditadura militar que suas fardas verde oliva aparecessem em cores vibrantes nas telinhas de todos os brasileiros, mostrando ao vivo e em cores no Jornal Nacional que o Brasil ia "às mil maravilhas". Possibilitando que o presidente Médici, no dia 21 de março de 1973, no Palácio do Planalto, observando que 1973 "seria um ano difícil”, comentasse que se sentia feliz, todas as noites, ao chegar em casa e assistir ao telejornal, pois enquanto as notícias davam conta de greves, agitações, atentados e conflitos armados em várias partes do mundo, o Brasil marchava em paz, rumo ao desenvolvimento. "É como se fosse um tranquilizante, após um dia de trabalho". ${ }^{16}$

\footnotetext{
${ }^{16}$ O comentário do general-presidente estampou a primeira página do dia seguinte de Jornal do Brasil e O Estado de S. Paulo, mas não ganhou a primeira página de O Globo.
} 


\section{Referências}

A CÔR, enfim. Veja, São Paulo, n. 111, p. 85, 21 out. 1970.

A IMATURA emoção da cor. Veja, São Paulo, n. 146, p. 84, 23 jun. 1971.

A NOVELA da cor. Veja, São Paulo, n. 222, p. 94, 7 dez. 1972.

A TV em cores no primeiro dia. Veja, São Paulo, n. 187, p. 78, 5 abr. 1972.

ANDRADE, Valério. A vitória do teste. Jornal do Brasil, Rio de Janeiro, ano LXXXI, n. 270, p. 57, 22 fev. 1972.

AS CORES brasileiras, Jornal do Brasil, Rio de Janeiro, ano LXXXI, n. 150, p. 52, 30 set. 1971.

AS IMAGENS da dúvida. Veja, São Paulo, n. 109, p. 72, 7 out. 1970.

BARROS FILHO, Eduardo Amando de. A Fundação Centro Brasileiro de TV

Educativa: debates, projetos e práticas à produção e difusão de conteúdos teleeducativos na Ditadura Militar, 1964-1981. 2017. 301 f. Tese (Doutorado em História e Sociedade) - Faculdade de Ciências e Letras, Universidade Estadual Paulista (Unesp), Assis, 2017.

BOLAÑO, César. Mercado brasileiro de televisão. Aracaju: Proex/Cecac/Programa Editorial, 1988.

BORGES, Nilson. A Doutrina de Segurança Nacional e os governos militares. In: FERREIRA, Jorge; DELGADO, Lucilia de Almeida Neves (orgs.). O Brasil republicano. Rio de Janeiro: Civilização Brasileira, 2003. v. 4. p. 13-42. (O tempo da ditadura: regime militar e movimentos sociais em fins do século XX).

BUCCI, Eugênio. Brasil em tempo de TV. São Paulo: Boitempo, 1996.

BUCCl, Eugênio (org.). A TV aos 50: criticando a televisão brasileira no seu cinquentenário. São Paulo: Perseu Abramo, 2000. 
BUSETTO, Áureo. Sem aviões da Panair e imagens da TV Excelsior no ar: um episódio sobre a relação regime militar e televisão. In: KUSHNIR, Beatriz (org.).

Maços na gaveta: reflexões sobre mídia. Niterói: EdUFF, 2009. p. 53-63.

CANAL 4 lançou anteontem em São Paulo a televisão em cores. Diário de S.

Paulo, São Paulo, p. 4, 3 maio 1963.

CAPARELLI, Sérgio. Televisão e capitalismo no Brasil. Porto Alegre: L\&PM, 1982.

COMERCIAIS em três cores. Veja, São Paulo, n. 50, p. 60, 20 ago. 1969.

COMÉRCIO já vende a TV a cores. Jornal do Brasil, Rio de Janeiro, ano LXXXI, n. 260, p. 28, 8 fev. 1972.

COMPRADORES de TV colorida deve seguir rigorosamente as instruções do manual. Jornal do Brasil, Rio de Janeiro, ano LXXXI, n. 265, p. 14, 14 fev. 1972.

CONGRESSO de telecomunicações verá novidades sobre TV a cores no país. O

Globo, Rio de Janeiro, ano XLI, n. 12294, p. 3, 8 jun. 1966.

CORES sem festa. Veja, São Paulo, n. 185, p. 76, 22 mar. 1972.

CORONEL acha que a má informação adiou a TV a cores. Jornal do Brasil, Rio de Janeiro, ano LXXVIII, n. 99, p. 6, 3 ago. 1968.

CORSETTI fixa o prazo da televisão a cores. Jornal do Brasil, Rio de Janeiro, ano LXXX, n. 75, p. 6, 3 jul. 1970.

CORSETTI quer TV sadia e não divertindo o público com as misérias alheias. Jornal do Brasil, Rio de Janeiro, ano LXXXI, n. 139, 17 set. 1971a.

CORSETTI nega que empresa privada esteja contra ação do Govêrno pela TV a cores. Jornal do Brasil, Rio de Janeiro, ano LXXXI, n. 217, 17 dez. 1971b.

CORSETTI quer cadeia transmitindo em cores. Jornal do Brasil, Rio de Janeiro, ano LXXXI, n. 273, p. 22, 5 fev. 1972.

ENTRE as cores e o melhor nível, Veja, São Paulo, n. 176, p. 44, 12 jan. 1972. 
ESPERE pela cor. Veja, São Paulo, n. 119, p. 84, 16 dez. 1970.

ESTOQUE de TV a cores pode ser pequeno para o consumo. Jornal do Brasil, Rio de Janeiro, ano LXXXI, n. 259, p. 55, 7 fev. 1972.

EXPLOSÃO da cor. Veja, São Paulo, n. 297, p. 87, 15 maio 1974.

FÁBRICAS só no próximo mês começam a entregar aparelhos a cores. Jornal do Brasil, Rio de Janeiro, ano LXXXI, n. 231, p. 14, 5 jan. 1972a.

FÁBRICAS esperam êste ano vender 72 mil aparelhos de TV a côres em todo o país. Jornal do Brasil, Rio de Janeiro, ano LXXXI, n. 261, p. 26, 9 fev. 1972b.

FICO, Carlos. Reinventando o otimismo: ditadura, propaganda e imaginário social no Brasil. Rio de Janeiro: FGV, 1997.

GOVERNO não quer agora TV a cores. O Globo, Rio de Janeiro, ano XLV, n. 13493, p. 4, 4 maio 1970.

JEANNENEY, Jean-Noël. Uma história da comunicação social. Lisboa: Terramar, 1996.

LEAL FILHO, Laurindo. Atrás das câmeras: relações entre cultura, Estado e televisão. São Paulo: Summus, 1988. p. 38.

MATTOS, Sérgio Augusto Soares. História da televisão brasileira: uma visão econômica, social e política. Petrópolis: Vozes, 2002.

MÉDICl inaugura a Festa da Uva e fecha Rodeio Crioulo. Jornal do Brasil, Rio de Janeiro, ano LXXXI, n. 269, p. 3, 21 fev. 1972.

O FUTURO colorido. Veja, São Paulo, n. 96, p. 62, 8 jul. 1970.

OLIVEIRA, Lúcia Maciel Barbosa de. "Nossos comerciais, por favor!”: a televisão brasileira e a Escola Superior de Guerra - o caso Flávio Cavalcanti. São Paulo: Beca Produções Culturais, 2001. 
PALHA, Cássia Rita Louro. A Rede Globo e o seu repórter: imagens políticas de Teodorico a Cardoso. 2008. Tese (Doutorado em História) - Universidade Federal Fluminense, Niterói, 2008.

PIONEIRISMOS. Veja, São Paulo, n. 182, p. 69, 1 mar. 1972.

PRESIDENTE Goulart congratula-se com a TV Tupi pelo pioneirismo. Diário de S. Paulo, São Paulo, p. 8, 8 maio 1963.

PROVÁVEL demissão de Simas leva o CONTEL a reexaminar o problema da TV colorida. Jornal do Brasil, Rio de Janeiro, ano LXXVIII, n. 103, p. 18, 8 ago. 1968.

RIBEIRO, Ana Paula Goulart; SACRAMENTO, Igor; ROXO, Marco (org.). História da televisão no Brasil: do início aos dias de hoje. São Paulo: Contexto, 2010.

SIMAS altera portaria da TV em cores. Jornal do Brasil, Rio de Janeiro, ano LXXVIII, n. 109, p. 4, 5 ago. 1968a.

SIMAS volta atrás e permite televisão a côr antes de 1971. Jornal do Brasil, Rio de Janeiro, ano LXXVIII, n. 104, p. 11, 9 ago. 1968b.

TELEVISÃO gaúcha inaugura televisão a côres no país com filme japonês. Jornal do Brasil, Rio de Janeiro, ano LXXXI, n. 263, p. 6, 11 fev. 1972.

TOSTES, Octávio. A cor do milagre: o advento da TV em cores no Brasil do regime militar. 2013, 130 f. Dissertação (Mestrado em História) - Universidade de São Paulo (USP), São Paulo, 2013.

TV: as cores estão chegando. Veja, São Paulo, n. 90, p. 36, 27 maio 1970a.

TV a Educar. Jornal do Brasil, Rio de Janeiro, ano LXXX, n. 76, p. 6, 4 jul. $1970 b$.

TV a cores inicia operação normal a 31 de março de 72. Jornal do Brasil, ano LXXX, n. 212, p. 13, 10 dez. 1970c.

TV a cores: mais aparelhos dependem dos fabricantes. O Globo, Rio de Janeiro, ano XLVII, n. 13943, p. 8, 16 out. 1971. 
TV a cores fará dois programas. Jornal do Brasil, Rio de Janeiro, ano LXXXI, n. 267, 18 fev. 1972.

TV em cores aluguel. Jornal do Brasil, Rio de Janeiro, ano LXXXIII, n. 246, p. 14, 10 dez. 1973.

XAVIER, Ricardo; SACCHI, Rogério. Almanaque da TV: 50 anos de memória e informação. Rio de Janeiro: Objetiva, 2000. 